\title{
LA PORTADA DEL CONVENTO DE SAN LORENZO DE MONTILLA (CÓRDOBA): NUEVAS APORTACIONES SOBRE SU DEFINICIÓN ARQUITECTÓNICA Y ANÁLISIS ICONOGRÁFICO
}

\author{
ELENA BELLIDO VELA \\ Fundación Biblioteca Manuel Ruiz Luque
}

\section{Resumen}

El presente trabajo tiene como objetivo el estudio de la portada del desaparecido convento de San Lorenzo de Montilla (Córdoba) desde un punto de vista arquitectónico y de sus elementos artísticos, correspondiente al período renacentista. Para ello se ha realizado un seguimiento de su configuración constructiva a través de modelos de la Antigüedad Clásica y de los tratados de Diego de Sagredo y Hernán Ruiz II. El estudio iconográfico planteado demuestra la armonía entre elementos cristianos con otros de raigambre clásica. Como conclusión, esta portada manifiesta la plena asimilación del pensamiento humanista mediante la utilización de un lenguaje arquitectónico y plástico que sigue modelos del renacimiento, exaltando la identidad de la II marquesa de Priego a través de la utilización de motivos de reconocida firmeza imperial.

\section{Palabras clave}

Convento de san Lorenzo. Montilla. Arquitectura renacentista. Marquesado de Priego. Catalina Fernández de Córdoba.

\section{THE MAIN FRONT OF THE CONVENT OF SAN LORENZO OF MONTILLA (CÓRDOBA): NEW CONTRIBUTION ON ITS ARCHITECTURAL DEFINITION AND ICONOGRAPHIC ANALYSIS}

\begin{abstract}
The present work has as object the study of the main front of the disappeared convent of San Lorenzo of Montilla (Córdoba) from an architectural point of view and its artistic elements, corresponding to the Renaissance period. For it, a continuation of its constructive configuration through models of Classical Antiquy has been carried out and Diego de Sagredo and Hernán Ruiz II treatises. The planned iconographic study demonstrates the dialectical harmony established between Christian elements with others of classical tradition. In conclusion, this main front shows the assimilation of the humanist though through the use of an architectural and plastic language that follows Renaissance models, extolling the identity of the II Marquise of Priego through the use of motives of recognized imperial firmness.
\end{abstract}

Key words

San Lorenzo convent. Montilla. Renaissance architecture. Marquisate of Priego. Catalina Fernández de Córdoba. 
La portada que daba acceso al desaparecido convento de San Lorenzo de Montilla (Córdoba), encuadrada en el primer renacimiento ${ }^{1}$, se constituye como el único vestigio del conjunto arquitectónico que se ha conservado en la actualidad, a pesar de que en los últimos años ha sufrido un preocupante deterioro (fig. 1 y fig. 2).Como se recoge en la crónica manuscrita de Francisco Angulo, el establecimiento franciscano fue edificado entre los años 1525 y 1530 en una huerta situada extramuros de la localidad en dirección noreste ${ }^{2}$, siguiendo las pautas constructivas que caracterizaban la tipología conventual observante imperante por entonces $^{3}$. La extrema sobriedad estructural y modestia de materiales que presentaba el edificio instó a Catalina Fernández de Córdoba (ca. 1495-1569), impulsora de la construcción, a que se realizaran una serie de mejoras de índole arquitectónico y de dotación ornamental, dado que la iglesia conventual habría de acoger el panteón familiar del marquesado de Priego. Podemos advertir que estas intervenciones estuvieron pensadas para mostrar el poder y magnificencia de los Fernández de Córdoba — de la Casa de Aguilar-, uno de los linajes más importantes de Andalucía durante la Baja Edad Media y la Edad Moderna. Pero al mismo tiempo también manifiestan el elevado conocimiento que la II marquesa de Priego disponía con respecto a las tendencias artísticas renacentistas del momento que le tocó vivir.

Las actuaciones de mejora que Catalina Fernández de Córdoba mandó efectuar en el recinto conventual fueron ejecutadas durante los últimos años de su gobierno, estando centradas principalmente en la iglesia, en la capilla funeraria, así como en una monumental portada ${ }^{4}$. En efecto, se acometieron importantes obras de reparación edilicia en los referidos enclaves, dado que estaban gravemente afectados por la excesiva humedad del terreno ${ }^{5}$. Un retablo de trazas renacentistas se colocó en la capilla mayor, en 1566, cuyo dorado y decoración pictórica fueron ejecutados por Francisco de Castillejo, como indican Lorenzo Muñoz y Garramiola Prieto ${ }^{6}$. Al mismo artífice se debe el dorado y pintado de la verja de

\footnotetext{
${ }^{1}$ Sebastián, 1991:103-107. Aunque las escasas referencias historiográficas que abordan esta portada la califican con el término "plateresco», pensamos que, como manifiesta Santiago Sebastián, este concepto puede ser considerado erróneo al haber quedado superado. En efecto, siguiendo al autor citado, se han producido cambios sustanciales en las investigaciones sobre el primer renacimiento, y lejos de continuar con la terminología adoptada por Ortiz de Zúñiga en el siglo XVII -que le concede un carácter eminentemente hispánico-, las investigaciones iniciadas por Rosenthal y continuadas posteriormente por otros historiadores, como Nieto Alcaide, demuestran que las manifestaciones artísticas del erróneamente llamado plateresco tienen su génesis en las fuentes italianas, así como las relaciones y paralelismos con respecto a otras obras realizadas en otros países europeos. De esta forma, los resultados de las investigaciones inducen a llamar a este estilo como primer renacimiento o protorrenacimiento.

${ }^{2}$ Las fuentes manuscritas y bibliográficas manejadas para el estudio del convento de San Lorenzo han sido las siguientes: Angulo, 1590, Fundaciones de los conventos de San Esteban de Priego y San Lorenzo de Montilla, Fundación Biblioteca Manuel Ruiz Luque, Montilla (FBMRL), Ms. 313, ff. 185r-258v. Se trata de la principal fuente documental de la que se sirven el resto de autores que abordan este asunto. Arroyo, 1741, Estracto[sic] de la fundación y cosas memorables de este Convento de Sn. Laurencio de Montilla (FBMRL), Ms. 313, ff. 259r-270v. Jurado, 1776, Ulia Ilustrada y fundación de Montilla. Historia de las dos ciudades (FBMRL), Ms. 103, ff. 244v-267r. Lorenzo, 1779, Historia de la M.N.L. ciudad de Montilla (FBMRL), Ms. 54, ff. 84-89. Testimonio en que consta que los Marqueses de Priego eran fundadores y patronos del convento de San Lorenzo de la orden de san Francisco, extramuros de Montilla, 21 de mayo de 1733, Archivo Ducal de Medinaceli, Sevilla (ADM), Sección Priego, legajo 2, núm. 10, s.f. Torres, 1683: 116-121. Morte, 1982: 88-90. Garramiola, 1982: 160-162

3 Con respecto al estudio de la arquitectura franciscana, como obras referenciales se han consultado: Cuadrado, 1991a:15-70; 1991b: 479-552. García Ros, 2000.

${ }^{4}$ Bellido, Elena (2019): "El desaparecido convento franciscano de San Lorenzo de Montilla. Definición geométrica y representación gráfica”. Tesis Doctoral. Universidad de Córdoba, 2019.

En: https://helvia.uco.es/xmlui/handle/10396/17965 [Fecha de consulta: 06-05-2019]. Sobre las intervenciones arquitectónicas y artísticas realizadas a instancias de la II marquesa de Priego en el convento de San Lorenzo véase el apartado 5.2.5.

5 Angulo, 1590, Fundaciones de los conventos de San Esteban de Priego y San Lorenzo de Montilla (FBMRL), Ms. 313, ff. 194r y 198 v. El autor indica que «mucha parte del año salía de la bóveda de los Señores un gran golpe de agua que corría por la iglesia, claustro y de profundis». La filtración emergía debido a la obstrucción de una canalización hídrica subterránea, por lo que las obras de reparación consistieron principalmente en la desecación del terreno mediante zanjas y en la reparación y desviación de dicha atarjea.

${ }^{6}$ Angulo, 1590, Fundaciones de los conventos de San Esteban de Priego y San Lorenzo de Montilla, (FBMRL), Ms. 313, f. 198v. Lorenzo, 1779, Historia de la M.N.L. ciudad de Montilla (FBMRL), Ms. 54, f. 86. Garramiola, 1986:
} 


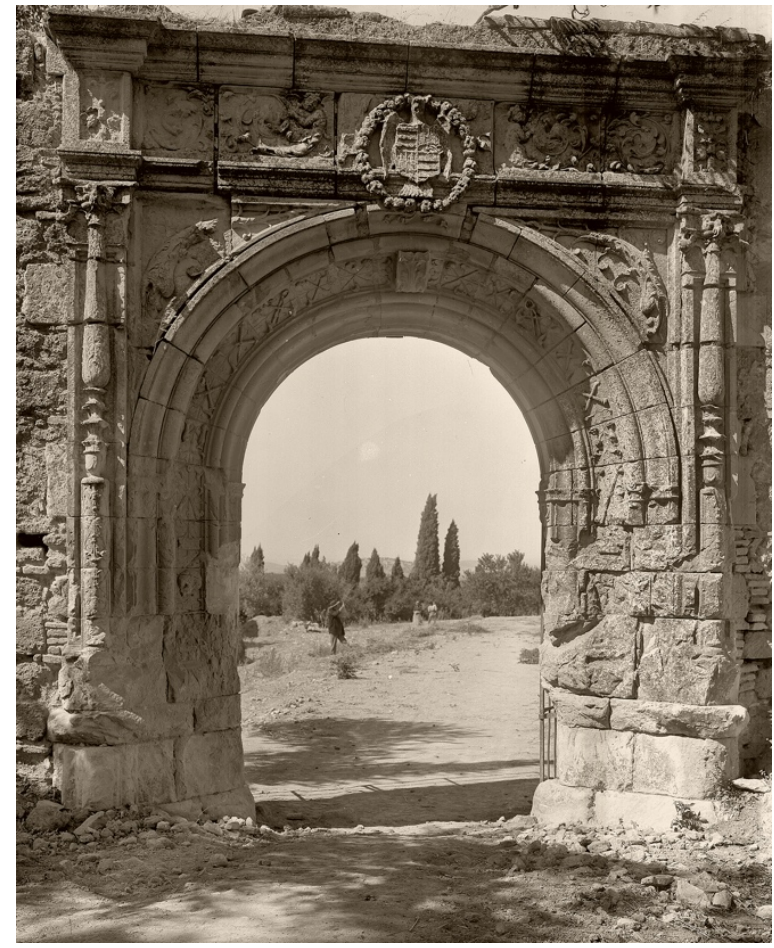

Fig. 1. Portada del convento de San Lorenzo, ca. 1917. Montilla (Córdoba). Fuente: Archivo de Agustín Jiménez Castellanos

hierro forjado que también en aquel momento se instaló en el arco toral del presbiterio, compuesta de enrejados en los que se intercalaban ramos de flores sobredorados . Además, la estructura del panteón perteneciente al linaje de la Casa de Aguilar —ubicado en el lado del Evangelio del presbiterio-, fue ampliada mediante la elevación de la construcción con una nueva cubierta a modo de bóveda semiesférica«que coge toda la capilla» ${ }^{8}$, según describe Torres. Por el dibujo que realizó el arquitecto Juan Antonio Camacho en 1723 sabemos que la bóveda descansaba sobre tambor y se trasdosaba al exterior ${ }^{9}$. El recinto funerario quedaba delimitado mediante una verja «al modo de las que están en la Capilla Real de Granada» ${ }^{10}$, según deseo de la II marquesa de Priego.

Asimismo, el exterior de la fachada principal del templo hubo de beneficiarse de estas actuaciones, ya que, con bastante probabilidad, la portada original habría de reducirse a la máxima sencillez franciscana observante. Según se deduce de las descripciones que nos dejaron distintos autores que hubieron de conocer la construcción ${ }^{11}$, así como por el

42-43. Según consta en el contrato dado a conocer por Garramiola, el retablo habría de ser «estofado de esta manera, sobre el oro los campos de los frisos de toda la talla han de ir de oro y los frutos y hojas estofadas [...] al natural algunos campos de las tajas de azul y esgrafiados de ricos colores azules, carmines todos de Indias, que sean muy finos [...] en las columnas, los paños que tienen colgando, hechos almaizares al natural, estofado sobre oro como dicho tengo de ricos colores».

${ }^{7}$ Valoración de bienes pertenecientes al convento franciscano de San Lorenzo de Montilla para destinarlo como seminario de misioneros franciscanos de la provincia franciscana descalza de San Gregorio de Filipinas, 20 de agosto de 1796, Archivo Franciscano Ibero Oriental, Madrid, (AFIO), Leg.105, no14, f. 26. De la Torre, 1988:162.

8 Torres, 1683:118.

${ }^{9}$ Camacho, Juan Antonio (1723): "Descripción del plano sexto en el que se demuestra la planta superfizial y el alzado della magnifica y sumptuosa enfermería: que a espensas del Excmo. S. D. Nicolás Fernández de Córdoba [...] se ha executado en el M. R. Convto. De No. Pe. Sn. Franco. Con la advocación de Sn Lorenzo extramuros de la ciudad de Montilla". http://www.juntadeandalucia.es/institutodeestadisticaycartografia/cartoteca/buscar/getetiqueta/id/29788 [Fecha de consulta: 02-05-2019].

10 Angulo, 1590, Fundaciones de los conventos de San Esteban de Priego y San Lorenzo de Montilla, (FBMRL), Ms. 313, ff. $195 \mathrm{r}$ y $197 \mathrm{r}$. Torres, 1683:118.

${ }^{11}$ Lorenzo, 1779, Historia de la M.N.L. ciudad de Montilla (FBMRL), Ms. 54, f. 86. El autor indica que: «En el frontis principal está la portada de la iglesia, con pinturas de talla en la piedra muy especiales». Jurado, 1776, Ulia Ilustrada y fundación de Montilla. Historia de las dos ciudades (FBMRL), Ms. 103, f. 248 v. Al respecto nos dice que la 
Fig. 2. Portada del convento de San Lorenzo, 2005. Montilla (Córdoba). Fuente: fotografía de la autora.

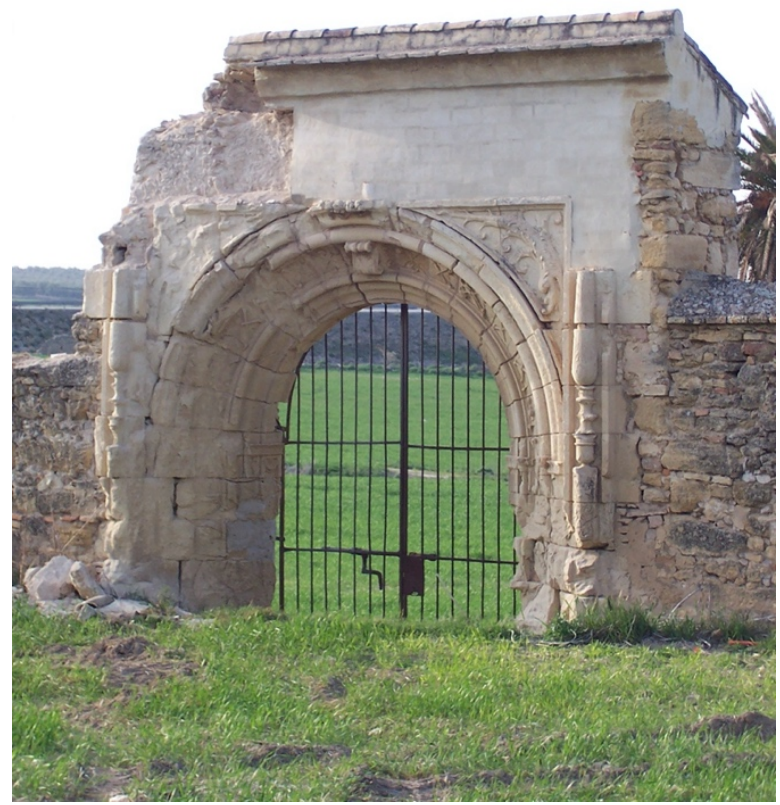

mencionado dibujo realizado por Juan Antonio Camacho ${ }^{12}$, pensamos que el acceso de la iglesia se enriqueció con una decoración acorde al periodo artístico en el que se ejecutó, en el que aún tenían vigencia los repertorios del primer renacimiento.

A tenor de la documentación manejada advertimos que Catalina Fernández de Córdoba siguió puntualmente el curso de estas intervenciones arquitectónicas y ornamentales, destinadas a magnificar en cuanto pudo la fundación religiosa que, auspiciada por sus ascendientes, estaba destinada a acoger el panteón familiar de su noble parentela ${ }^{13}$. Al respecto, como indica Angulo, sabemos que la aristócrata se implicó de lleno en precisar las particularidades de cada una de las aportaciones señaladas y de la elección de piezas artísticas, así como la contratación de maestros, sin escatimar en lo referente a valiosos materiales y en la aplicación de costosas técnicas artísticas ${ }^{14}$. Sin lugar a dudas, la II marquesa de Priego quiso remediar la sobriedad de la fundación franciscana de San Lorenzo de Montilla mediante las realizaciones descritas. De esta forma dejaba constancia de su patronazgo con el claro interés de exaltar su distinguido linaje a través de la promoción de las artes y, concretamente, de la

portada era «de piedra franca y sencilla, tallada a la perfección». En cualquier caso, estas aportaciones renacentistas pueden relacionarse con las efectuadas en la portada sur de la parroquia de Nuestra Señora del Soterraño de Aguilar de la Frontera (Córdoba), que advirtió importantes modificaciones a instancias de la II marquesa de Priego.

12 Camacho, Juan Antonio (1723): "Descripción del plano sexto en el que se demuestra la planta superfizial y el alzado della magnifica y sumptuosa enfermería: que a espensas del Excmo. S. D. Nicolás Fernández de Córdoba [...] se ha executado en el M. R. Convto. De No. Pe. Sn. Franco. Con la advocación de Sn Lorenzo extramuros de la ciudad de Montilla". http://www.juntadeandalucia.es/institutodeestadisticaycartografia/cartoteca/buscar/getetiqueta/id/29788 [Fecha de consulta: 02-05-2019].

13 Bellido, Elena (2019): "El desaparecido convento franciscano de San Lorenzo de Montilla. Definición geométrica y representación gráfica”. Tesis Doctoral. Universidad de Córdoba, 2019.

En: https://helvia.uco.es/xmlui/handle/10396/17965 [Fecha de consulta: 06-05-2019]. Los capítulos IV y $\mathrm{V}$ abordan el proceso fundacional del convento de San Lorenzo.

${ }^{14}$ Angulo, 1590, Fundaciones de los conventos de San Esteban de Priego y San Lorenzo de Montilla, (FBMRL), Ms. 313, ff. 195r y 198v. Sobre este particular, el autor informa que «todo pasaba por sus manos y por sus ojos». Garramiola, 1986: 42-43. 
simbología de elementos renacentistas que quedaron plasmados en la monumental portada de acceso al recinto conventual, objeto de estudio de este trabajo.

En efecto, la circunstancia de que el establecimiento franciscano se encontrara en una parcela ubicada extramuros de Montilla, conocida como huerta del Adalid, determinó que el terreno quedara cercado con una tapia de mampostería de piedra arenisca que lo circunscribía, permitiendo el paso mediante la señalada portada, enclavada en el flanco meridional. Las fuentes documentales que se disponen sobre los acontecimientos que hubieron de rodear su construcción son ciertamente escasas. Hasta el momento no se han localizado noticias fehacientes que aporten datos relativos a su cronología exacta o el maestro encargado de ejecutarla ${ }^{15}$. A pesar de la excepcional calidad artística que manifiesta esta obra, las fuentes antiguas - manuscritas e impresas-, así como las gráficas utilizadas eluden por completo su existencia ${ }^{16}$. No es hasta mediados del siglo XIX, estando el edificio conventual prácticamente desaparecido, cuando Ramírez de las Casas Deza realiza una primera valoración artística: «se conserva aún la portada entera que es de mármol blanco y de un trabajo tan precioso como prolijo» ${ }^{17}$. Sin embargo, a pesar de la elogiosa estimación cuestionamos que el erudito cordobés visitase el convento de San Lorenzo de Montilla, ya que el material con el que se erigió la portada no se corresponde con el expresado.

Sin embargo esta laguna documental queda, en cierto modo, compensada con algunos indicios que pudieran auxiliarnos sobre este asunto, a través de los cuales se plantearán algunas conclusiones en cuanto a la fecha aproximada de su ejecución e influencias estilísticas. En efecto, según relata Angulo, en 1572 se plantaron los álamos y cipreses que rodeaban la cerca ${ }^{18}$, de modo que el elemento delimitador hubo de levantarse en una fecha anterior a la señalada. Pero, sin duda, el referente más clarificador es el motivo heráldico que presentaba la portada, perteneciente a las armas de la II marquesa de Priego, con lo cual no cabe duda que la portada hubo de erigirse durante su gobierno.

Además de las conjeturas señaladas, hemos de tener en cuenta las características artísticas y morfológicas que presenta la construcción, pudiéndose calificar de un primer renacimiento plenamente depurado. De esta forma, pensamos que, con bastante probabilidad, la portada hubo de ser culminada durante los años en los que la II marquesa de Priego ordenó realizar las mencionadas actuaciones de mejora en el convento franciscano observante, previamente a la inauguración de la capilla funeraria de los Fernández de Córdoba en $1566^{19}$.

Existen dos factores que permiten considerar la portada del convento de San Lorenzo como referente del renacimiento cordobés. Por un lado, su definición arquitectónica, trasmisora del ideal clásico y, por otro, todo lo concerniente a la ornamentación, supeditada a su composición estructural. Con respecto a lo último hemos de incluir tanto el excepcional

${ }^{15}$ Con este interés se han consultado los fondos documentales pertenecientes al Ducado de Medinaceli, sección Priego, en el Archivo General de Andalucía.

${ }^{16}$ Los autores que venimos citando en relación al convento de San Lorenzo muestran un silencio absoluto con respecto a la portada de acceso: Angulo, 1590, Fundaciones de los conventos de San Esteban de Priego y San Lorenzo de Montilla, (FBMRL), Ms. 313, ff. 185r-258v. Torres, 1683:116-121. Lorenzo, 1779, Historia de la M.N.L. ciudad de Montilla (FBMRL), Ms. 54, ff. 84-89. Jurado, 1776, Ulia Ilustrada y fundación de Montilla. Historia de las dos ciudades (FBMRL), Ms. 103, ff. 244v-267r. Morte, 1982: 88-90. Camacho, Juan Antonio (1723): "Descripción del plano sexto en el que se demuestra la planta superfizial y el alzado della magnifica y sumptuosa enfermería: que a espensas del Excmo. S. D. Nicolás Fernández de Córdoba [...] se ha executado en el M. R. Convto. De No. Pe. Sn. Franco. Con la advocación de Sn Lorenzo extramuros de la ciudad de Montilla". En: http://www.juntadeandalucia.es/institutodeestadisticaycartografia/cartoteca/buscar/getetiqueta/id/29788

[Fecha de consulta: 02-05-2019]. Con respecto al dibujo de Camacho hemos de señalar que, a diferencia de otras portadas de menor empaque constructivo y artístico, la de acceso no queda efigiada.

17 Ramírez de las Casas Deza, 1986: 337.

${ }^{18}$ Angulo, 1590, Fundaciones de los conventos de San Esteban de Priego y San Lorenzo de Montilla, (FBMRL), Ms. 313, f. 208 r.

${ }^{19}$ Fernández de Córdoba, 1954: 179. Angulo, 1590, Fundaciones de los conventos de San Esteban de Priego y San Lorenzo de Montilla (FBMRL), Ms. 313, f. 199r. Sobre este particular, el autor indica que «todo concluido y ordenado mandó la marquesa sacar los huesos de sus padres y de su hijo mayor el Conde don Pedro y de un hijo suyo que murió pequeñito y de una hija del duque de Arcos que estaban depositados en la iglesia mayor de Santiago. De allí los trajeron al convento de San Francisco». 


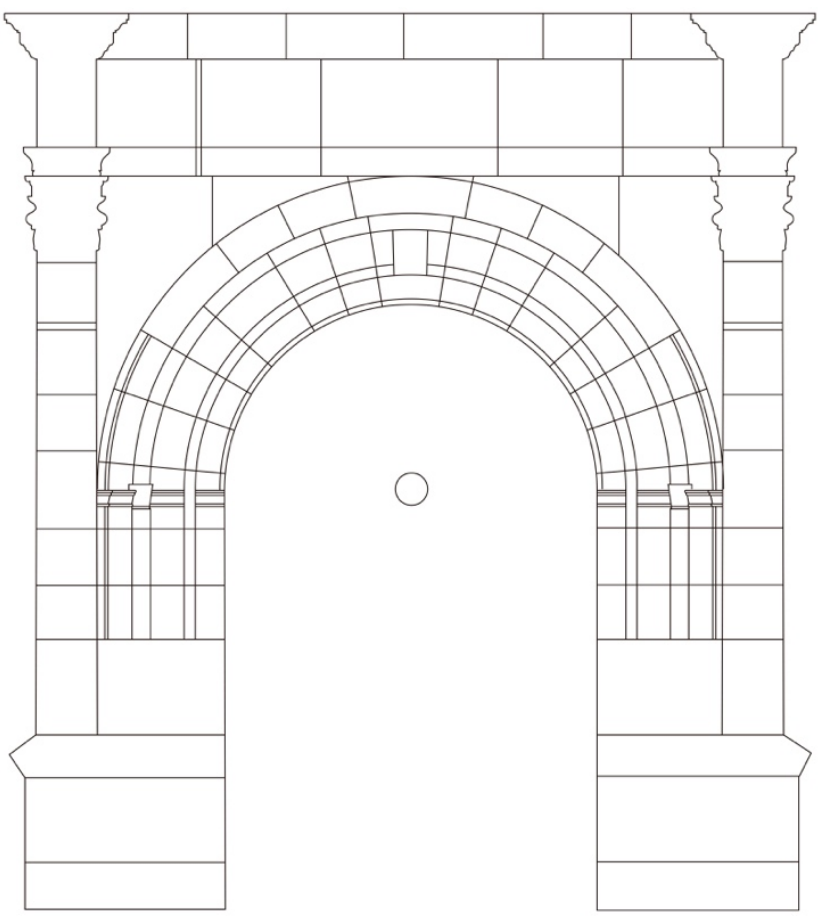

Fig. 3. Alrado de la portada del convento de San Lorenzo, según Arturo Ramírez Laguna. Montilla (Córdoba). Fuente: Arturo Ramírez Laguna.

programa iconográfico desarrollado como la mano del anónimo escultor que lo ejecutó. Por ello, en esta construcción se sintetiza el sentido estético del arte renacentista, tanto desde el punto de vista arquitectónico como desde el plástico, aspectos se desarrollarán a continuación con mayor detalle.

\section{Arquitectura Renacentista De La Portada De San Lorenzo: Análisis Formal}

La composición arquitectónica de esta construcción manifiesta que el maestro que realizó su trazado disponía suficientes conocimientos del renacimiento como movimiento inspirado en la Antigüedad. Su definición estructural responde a la tipología de los arcos de triunfo romanos de un solo vano -fornices-, que tuvieron un carácter honorífico y conmemorativo, considerándose asimismo como puertas monumentales -ianua- que marcaban límites territoriales $^{20}$. Por lo tanto, este aspecto denota el dominio del anónimo artífice con respecto a las teorías y conceptos de arquitectura clásica, plenamente implantados en la fecha de su ejecución - en los años centrales del quinientos-, concretamente del tratado de Diego de Sagredo, Medidas del Romano, publicado en Toledo en 1526, y, principalmente, de la obra de Hernán Ruiz el Joven, como se verá con mayor detención ${ }^{21}$. Ello se manifiesta en las armónicas proporciones de la construcción, basadas en principios de geometría, las cuales proyectan el concepto de simetría en el sentido clásico del término, por cuanto que cada parte guarda relación con las demás, y éstas con el todo, elemento esencial de las construcciones clásicas (fig. 3) ${ }^{22}$. Obedeciendo, asimismo, al ideal de canon clásico que identifica las

${ }^{20}$ García Bellido, 1990: 54-56. González, 1985: 184-191.

${ }^{21}$ Sagredo, 1526: s.f. Ruiz, Hernán (ca. 1558-1569): “Tratado de Arquitectura”. En:

http://cdp.upm.es/view/action/nmets.do?DOCCHOICE $=436110 . x m l \& d v s=1570971357916 \sim 339 \& l o c a l e=$ es_ES\&search_terms =\&adjacency=\&VIEWER_URL=/view/action/nmets.do?\&DELIVERY_RULE_ID= $1 \&$ divType $=$ \&usePid1 $=$ true\&usePid2 $=$ true $[$ Fecha de consulta: 02-05-2019]. Este manuscrito se custodia en la Biblioteca de la Universidad Politécnica de Madrid. Dado que en este estudio planteamos una fecha de ejecución de la portada de San Lorenzo en los años centrales del siglo XVI, pensamos que aunque el Tratado de Arquitectura de Hernán Ruiz II aún no estaba en circulación, sus diseños de portadas eran lo suficientemente conocidos a través de su obra proyectada y construida.

${ }^{22}$ Mientras que el tratado de Sagredo, en la edición utilizada de 1526, únicamente recoge un dibujo de una portada con arco de medio punto, por el contrario hemos de señalar la riqueza gráfica de portadas centradas en arco de medio punto en el tratado de Hernán Ruiz II. Su gran variedad abarca desde diseños muy sencillos 
Fig. 4. Hernán Ruiz. Diseño de portada. Fuente: Biblioteca Universitaria UPM-ETS Arquitectura.

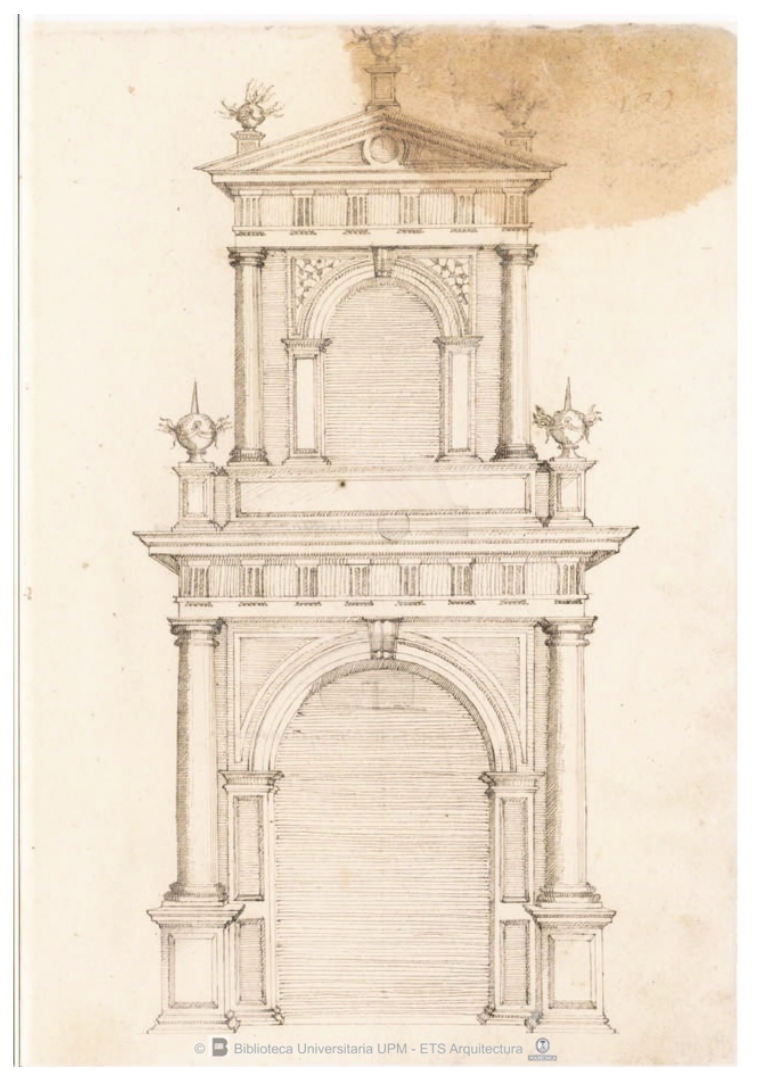

creaciones renacentistas desde que L.B. Alberti, fundador de la nueva visión humanista de las disciplinas artísticas, estableciera con sus escritos teóricos las bases para la unión entre arte y ciencia que sustentó el Renacimiento ${ }^{23}$.

Como ya se ha referido, ante el desconocimiento de fuentes documentales directas, barajamos la posibilidad de que esta construcción pudiera responder a varias fases de ejecución. Asimismo, pensamos que su definición arquitectónica revela un planteamiento que sigue con gran afinidad los modelos introducidos por Hernán Ruiz el Joven, quien, como indican distintos autores, alcanzó un protagonismo fundamental en los años centrales del siglo XVI en cuanto al asentamiento de modelos italianizantes en Andalucía $a^{24}$. De amplia formación humanística, según demuestra su faceta como tratadista, Manuscrito de Arquitectura, así como el dominio de autores clásicos como Vitruvio, y de los tratadistas Sagredo, Serlio y Alberti, transmite un ideal de arquitectura que encontramos en la portada de San Lorenzo y en otras construcciones enclavadas en el área cordobesa (fig. 4$)^{25}$. Sin embargo, como se verá en el análisis de sus formas, la portada también deja sentir ciertos elementos que pueden vincularse con modelos que preceden a los cánones del célebre arquitecto cordobés,

a base de dos cuerpos a base de estructura mixta de arco y dintel, mientras que otros entrañan una mayor complejidad estructural. Algunos de estos diseños quedan concretados en numerosas en obras realizadas en el área cordobesa, como la casa de los Páez de Castillejo, la puerta de la Redención de la catedral o la perteneciente a la iglesia de San Juan Bautista de Hinojosa del Duque.

${ }_{23}^{3}$ Revenga, 2016: 22-23. Heydenreich / Lotz, 1996: 62-63.

24 De la Banda, 1974: 85-91. Villar, 1986: 216-218. Jordano, Ma Ángeles (2017): “El palacio de los Páez de Castillejo. El ascenso social de un linaje".

En:https://dialnet.unirioja.es/buscar/documentos?querysDismax.DOCUMENTAL_TODO=Jordano+ Barbudo+palacio+paez [Fecha de consulta: 10-04-2019].

${ }^{25}$ Navascués, 1971:297-321.Según el autor, el manuscrito no se escribió para su publicación, sino para ser herramienta de trabajo de uso personal. En su contenido refleja la especial preocupación que Hernán Ruiz II mostró por la teoría de la arquitectura. Fue escrito en torno a 1558 y 1569, coincidiendo con su etapa de madurez, y recoge un excepcional repertorio de dibujos en los que se detecta una síntesis de su estilo y de su obra construida. 


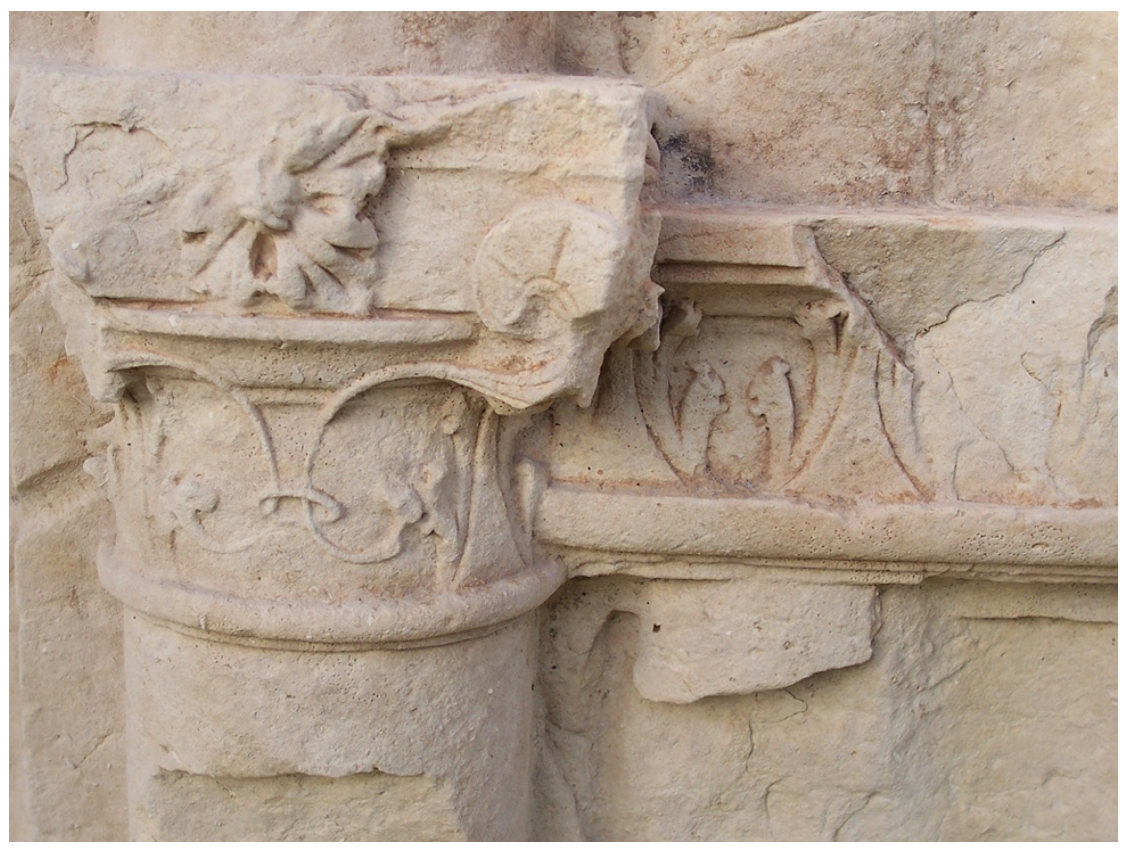

Fig. 5. Capitel de columna de las jambas de la portada del convento de San Lorenzo. Fuente: fotografía de 1n n..n+m

concretamente en aquellos fijados por Diego de Sagredo, justificando por ello que la construcción se hubiera realizado en distintas etapas.

La portada, que mide 5,10metros de alto y 4,40 de ancho, fue edificada con sillares de piedra calcarenita bioclástica caliza. Según Jiménez Espejo se trata de un material abundante en Montilla, procedente de alguna cantera de su entorno ${ }^{26}$. Centrándonos en su análisis constructivo, ésta se compone de una estructura interna a base de sillares de piedra caliza con mezcla de tapial, recubierta al exterior de piedra de mejor calidad y grano fino, más apropiada para esculpirla. Se eleva sobre sendos pedestales, a partir de los cuales se alzan sus respectivos pilares - de 1,15 m. de ancho- como elementos sustentantes. Una secuencia de baquetones a modo de columnillas con capiteles clásicos se apoya en cada uno de los mencionados pilares, estructurando las jambas y definiendo el nivel de la línea de imposta. Interesante es el diseño de los capiteles, que incluyen unas volutas invertidas que surgen de sendos filamentos curvos - unidos por un aro-, mientras una roseta centra el equino ${ }^{27}$ (fig. 5). Un esquema análogo, aunque carente de la destreza de los pertenecientes a la portada de San Lorenzo, se ha localizado en un capitel que se conserva en la que fue casa de la Compañía de Jesús de Montilla. Este elemento nos permite establecer ciertas concomitancias con respecto a la obra objeto de estudio tanto en la cronología, en los años centrales del siglo XVI, como en las iniciativas artísticas auspiciadas por la II marquesa de Priego ${ }^{28}$.

Asimismo, la prolongación de los baquetones siguiendo una tendencia curva permite la configuración del medio punto de la rosca del arco, que alcanza 2,10 m. de luz. A pesar del clasicismo dominante en el planteamiento general de esta portada, la sucesión de baquetones dispone cierto abocinamiento, aspecto que concede al conjunto un cierto matiz retardatario y se aleja de los modelos difundidos por Hernán Ruiz II en su tratado. De entre estas

\footnotetext{
26 Jiménez, 2004:106.

27 El esquema de la voluta invertida lo encontramos en un dibujo perteneciente a las adendas gráficas del final del tratado de Hernán Ruiz II.

${ }^{28}$ Este capitel reafirma nuestra opinión en cuanto a la fecha aproximada de la construcción de la portada, en los años centrales del siglo XVI, puesto que, aunque la fundación del Colegio de la Compañía de Jesús de Montilla se data en 1555, su actividad educativa comenzó tres años después, por lo que en este ínterin hubieron de realizarse las obras. Véase: Copado, 1944: 51-63.
} 
molduras, en las que se alternan cóncavas y convexas, la central es más ancha y plana que las colaterales, permitiendo incluir en sus dovelas decoración relivaria. El flanco interno presenta una sutil columna de tradición clásica. En la clave del arco destaca una ménsula de raigambre italianizante, elemento que se identifica en distintas obras del célebre arquitecto y tratadista cordobés, siendo constante su aparición en las ilustraciones de portadas en arco de medio punto recogidas en su tratado de arquitectura.

La portada de San Lorenzo queda encuadrada mediante sendas pilastras cajeadas, elemento que igualmente es recurrente en la obra de Hernán Ruiz II, las cuales disponen un leve avance con respecto al nivel de los pilares sustentantes. En cada una de las pilastras se inserta un balaustre, elemento que, desaparecido casi por completo del repertorio del que fue maestro mayor de obras de la catedral de Córdoba y de la de Sevilla, adquiere un notable resalte con respecto a aquellas. Un minucioso capitel jónico con las volutas dispuestas en diagonal corona cada uno de los balaustres. Con respecto al uso del balaustre hemos de indicar la relevancia que Diego de Sagredo le concedió en sus diseños, aunque con una función más ornamental que sustentante ${ }^{29}$.

Una cornisa cuya moldura dispone perfil recto y escalonado, siguiendo el modelo denominado $\left\langle\right.$ gradilla» ${ }^{30}$, se establece como elemento de transición entre el conjunto descrito y el entablamento superior. La superficie definida entre la parte lateral superior de las pilastras, la línea horizontal de la cornisa y la curvatura lateral del arco conforma sendas enjutas.

La portada culmina en un ancho ático, cuyo entablamento alcanza una altura de $0,50 \mathrm{~cm}$, destinado a acoger en su superficie motivos ornamentales. Este elemento queda delimitado en la parte inferior, como se ha indicado, por una moldura horizontal facetada en tres niveles. La cornisa superior, más ancha que la comentada, también se articulaba en tres fajas dispuestas en distintos niveles, pero quedaba enriquecida con otras molduras de perfil curvo, como queda representado en un dibujo del tratadista toledano ${ }^{31}$. De esta forma, la moldura inferior, convexa, se corresponde con la que se llama «talón», con respecto a la que ocupa la parte central, que es recta, el autor que se sigue no la considera moldura y la designa «cuadro [...] que se pone entre moldura y moldura para distinguir la una de la otra» ${ }^{32}$. Culminando la cornisa se encuentra otra moldura convexa, que sobresale con respecto a las anteriores, la cual sigue el modelo de talón.

Los flancos laterales del ático proyectan el leve avance de las pilastras cajeadas del cuerpo inferior, cuyo espacio rectangular también se reservó para incluir motivos decorativos de carácter figurativo. Este adelantamiento y diseño, propios de los modelos gráficos de Hernán Ruiz II, queda manifestado en el perfil quebrado de las cornisas. A modo de cerramiento, la portada hubo de disponer unas puertas de madera, como se advierte de la terminación de la parte posterior.

\section{Características artísticas y programa iconográfico de la portada de San Lorenzo}

La ornamentación escultórica de la portada de San Lorenzo se distribuye en distintos núcleos que, de manera armónica y ordenada, se organiza en función de su estructura arquitectónica a modo de arco triunfal. Excepcional es el tratamiento plástico, tanto por su realismo como por el hábil manejo de los volúmenes. En efecto, en los diversos motivos representados advertimos una gradual volumetría que va desde el alto relieve hasta llegar a la figuración de elementos que alcanzan efecto pictórico. Se trata de un efecto de perspectiva habitual en la ornamentación de la época.

A pesar de que buena parte de la decoración relivaria ha sufrido en los últimos años un deterioro alarmante, su elevado interés artístico nos ha impulsado a estudiar su composición así como a realizar su correspondiente análisis iconográfico, auxiliado por una fotografía

\footnotetext{
${ }^{29}$ Sagredo, 1526: s.f.

${ }^{30}$ Sagredo, 1526: s.f.

${ }^{31}$ Sagredo, 1526: s.f.

32Sagredo, 1526: s.f.
} 
Fig. 6. Diseño de la portada del convento de San Lorenzo, según Elena Bellido Vela. Montilla (Córdoba). Fuente: Elena Bellido Vela.

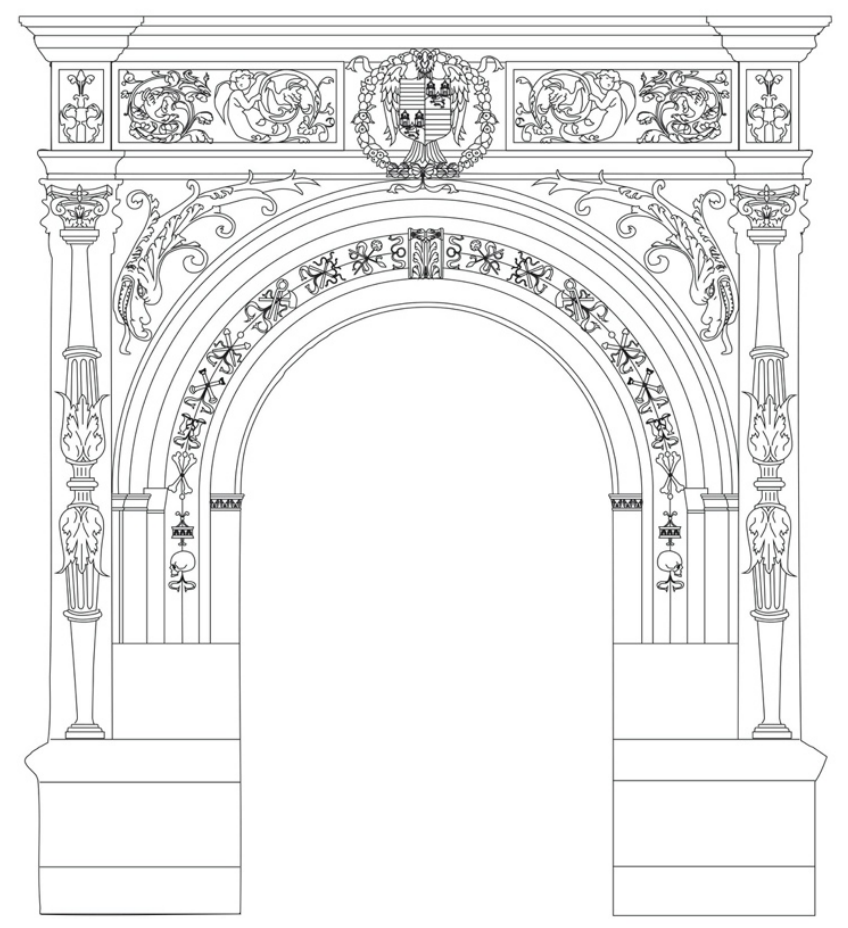

realizada en $1917^{33}$.Como se expondrá a continuación, los distintos enclaves decorativos establecen un orden jerarquizado, manteniendo una dialéctica entre elementos cristianos con otros pertenecientes a la Antigüedad Clásica, aspecto que manifiesta el ideal humanista basado en la «concordatio renacentista» ${ }^{34}$ (fig. 6).

Iniciaremos este estudio en las arquivoltas y su prolongación en las jambas, donde las dovelas y sillares presentan los instrumentos de la Pasión de Cristo. Se trata de una temática muy difundida por la Orden franciscana a través de la práctica del Vía Crucis ${ }^{35}$. Al respecto, conviene recordar la existencia de un Vía Crucis que recorría el trayecto establecido desde la salida de Montilla, por la calle Santa Brígida, hasta el convento de San Lorenzo, donde en su entrada culminaba la decimocuarta estación ${ }^{36}$.

Los instrumentos de la Pasión quedan dispuestos en sentido radial de las dovelas del arco de medio punto, mientras que los situados en las jambas están captados frontalmente. Cada motivo se sitúa simétricamente y por duplicado, es decir, se repiten los mismos elementos teniendo como eje de simetría la ménsula de la clave. Asimismo, en cada dovela se disponen los respectivos atributos pasionistas formando pareja, que están enlazados por cintas (fig. 7). Puede advertirse que los instrumentos emplazados en la rosca del arco quedan representados en sentido diagonal o cruzados, mostrando el siguiente orden: la lanza con la esponja; dos flagelos; dos clavos; el martillo y las tenazas; una pareja de fustes. Sin embargo, en la dovela inmediata al inicio de las jambas se muestran las dos jarras del lavatorio con una disposición paralela, a diferencia de los motivos anteriores, aunque también están unidas con un lazo. Esta captación, posiblemente, se debe al enfoque lineal que otorga su ubicación ${ }^{37}$.

${ }^{33}$ La imagen procede del archivo particular de Agustín Jiménez Castellanos.

34 Nieto/Checa, 1993: 108.

35 Cortés, 2012: 761.

${ }^{36}$ Jurado, 1776, Ulía Ilustrada y fundación de Montilla. Historia de las dos ciudades (FBMRL), Ms. 103, f. 250r. Lorenzo, 1779, Historia de la M.N.L. ciudad de Montilla (FBMRL), Ms. 54, ff. 170-171.De las fuentes consultadas se deduce que un primer Vía Crucis fue realizado en madera, siendo sustituido a principios del siglo XVII por otro realizado con sillares de piedra.

37 Bellido, 2009: 264. 


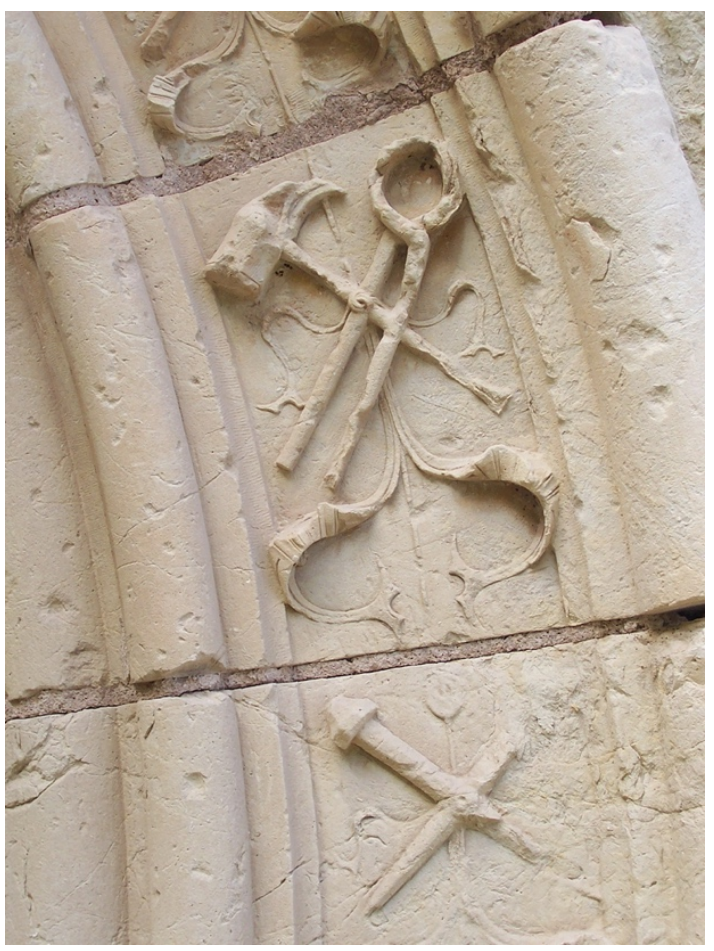

Fig. 7. Detalle Instrumentos de la Pasión de la portada del convento de San Lorenzo. Montilla (Córdoba). Fuente: fotografía de la autora.

Los motivos ubicados en los sillares de las jambas, de unas dimensiones algo mayores que las dovelas de la arcuación, quedarían a la altura de los ojos del espectador. En este espacio se introducen diversas representaciones vinculadas específicamente con el pasaje de la Crucifixión y muerte de Cristo, desaparecidas en la actualidad debido al deterioro sufrido en los últimos años. Al igual que en los comentados anteriormente, también se aprecia una correspondencia simétrica en la iconográfica, de forma que la secuencia que sigue evoca los siguientes motivos: las tibias entrecruzadas, el Santo Sepulcro y la calavera de Adán. Además podemos advertir que el conjunto de los elementos figurativos, tanto los dispuestos en la curvatura del arco como los de las jambas, parecen estar conectados por un sutil trazo, apenas esgrafiado, que los recorre. Esta delgada línea culmina en la ménsula central, quedando unida a ésta mediante sendas argollas que, ayudándose de lazos, están dispuestas en cada uno de sus lados.

De una forma generalizada encontramos en el modelado del conjunto escultórico una apreciable gradación volumétrica en cuanto a la técnica aplicada. Así, mientras los elementos que se localizan a mayor altura muestran un destacado relieve, los situados en las jambas son bastante más planos. Como se ha señalado, esta práctica responde a las correcciones ópticas y de perspectiva que se aplicaba a la decoración del primer renacimiento, y que podemos apreciar en la portada de San Lorenzo. Según este modo de proceder, se advierte cómo los motivos pasionistas situados en las dovelas más elevadas alcanzan tal resalte que parecen estar unidos a la superficie pétrea en un solo punto de unión. Igualmente, las cintas que los enlazan adquieren tal habilidad técnica que, en su representación, se percibe desde el más abultado volumen hasta llegar a un bajo relieve casi insinuado. Sin embargo, los instrumentos martiriales que se encuentran en las jambas muestran un procedimiento plástico distinto a los anteriores, ya que el modelado relivario es mucho más aplanado y superficial, pero, además, carecen de la pericia que adquieren los ubicados en las dovelas. Esta diferencia de 


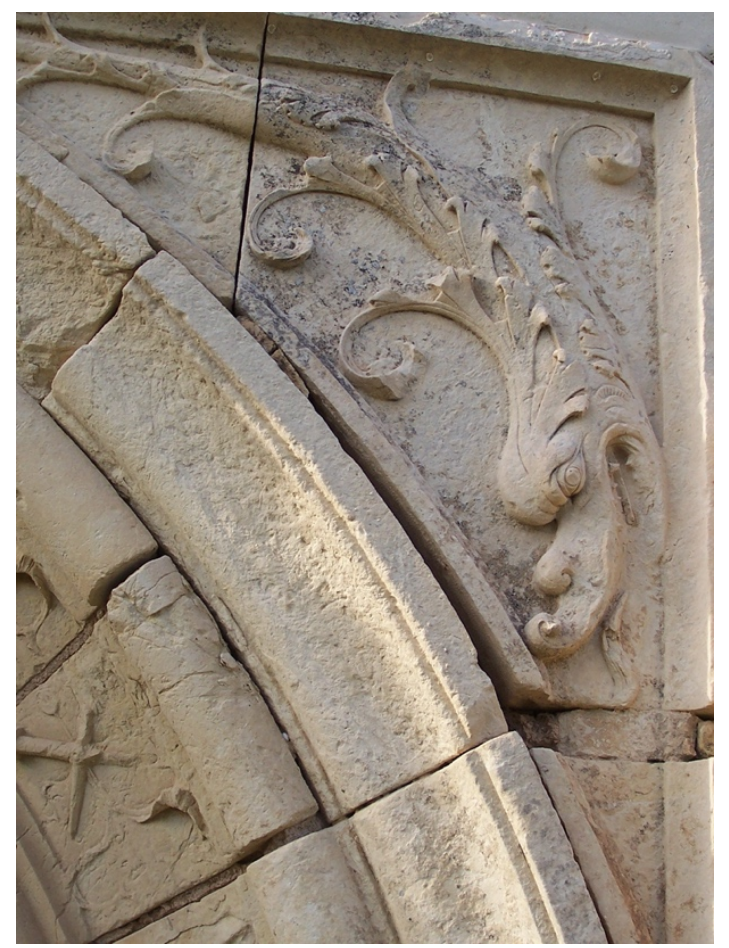

Fig. 8. Por menor. Enjuta de la portada del convento de San Lorenzo. Montilla (Córdoba). Fuente: fotografía de la autora.

calidades nos impulsa a pensar que el arco fue cincelado por diferentes maestros, tal y como queda justificado.

Siguiendo la decoración de la portada nos detendremos en las enjutas, donde en cada una se representa un animal fantástico que se asimila a un dragón (fig. 8). Su disposición se adapta ajustadamente a la superficie curvo-triangular de este espacio arquitectónico. Podemos apreciar cómo, al situarse en una posición un poco más elevada que los instrumentos de la Pasión, adquieren un mayor volumen con respecto a aquellos. Hemos encontrado semejanza de estos seres con los que aparecen en el tercer cuerpo de la fachada de la Universidad de Salamanca, tanto en el modelo iconográfico como en el tratamiento de su plasmación en el monumento montillano ${ }^{38}$. Este hecho nos induce a pensar que el artista encargado de diseñar los relieves de la portada laurenciana pudo tomar estos elementos decorativos propios del Quattrocento mediante grabados que, de una forma habitual en la época, circulaban por los talleres de escultores y canteros para componer repertorios iconográficos ${ }^{39}$. Asimismo, este motivo -el del monstruo-, lo hemos identificado en una serie de marcas tipográficas de impresores que trabajaron durante el segundo tercio del siglo XVI, concretamente del impresor y librero alemán afincado en Sevilla Jacobo Cromberger, y que, sin duda, fue tomado por los artistas para enriquecer sus trabajos ${ }^{40}$.

La influencia ejercida por los dibujos de Diego de Sagredo en los círculos artísticos renacentistas de mediados del quinientos fue prácticamente suplantada por la obra de Hernán Ruiz II, aunque no fue ajena al maestro que proyectó la portada de San Lorenzo, dando cuenta de ello en la interpretación de los balaustres (fig. 9 y fig. 10). Tal y como ilustra el tratadista toledano en Medidas del Romano, las secciones que componen dicho elemento están ornamentadas con hojas de acanto que le conceden un gran clasicismo. La aplicación del relieve es muy plana y minuciosa, adaptándose al formato de una forma muy lineal, casi insinuando la presencia vegetal. Asimismo, los distintos estrangulamientos de los balaustres

38 Checa, 1983: 34. Como señala el autor, la representación de estos animales fantásticos hunde sus raíces en los bestiarios medievales, siendo también acordes con la mentalidad renacentista y manierista que tanto se interesó por los gabinetes de fenómenos raros. Asimismo, este asunto iconográfico -el tema del monstruo-, puede relacionarse con la representación del pecado, con la experiencia del mal y el dolor, aunque en el caso que nos ocupa pensamos que su presencia se debe a la afinidad de este elemento al espacio a decorar.

39 Sebastián, 1991: 105.

40Vindel, 1942: 96. 


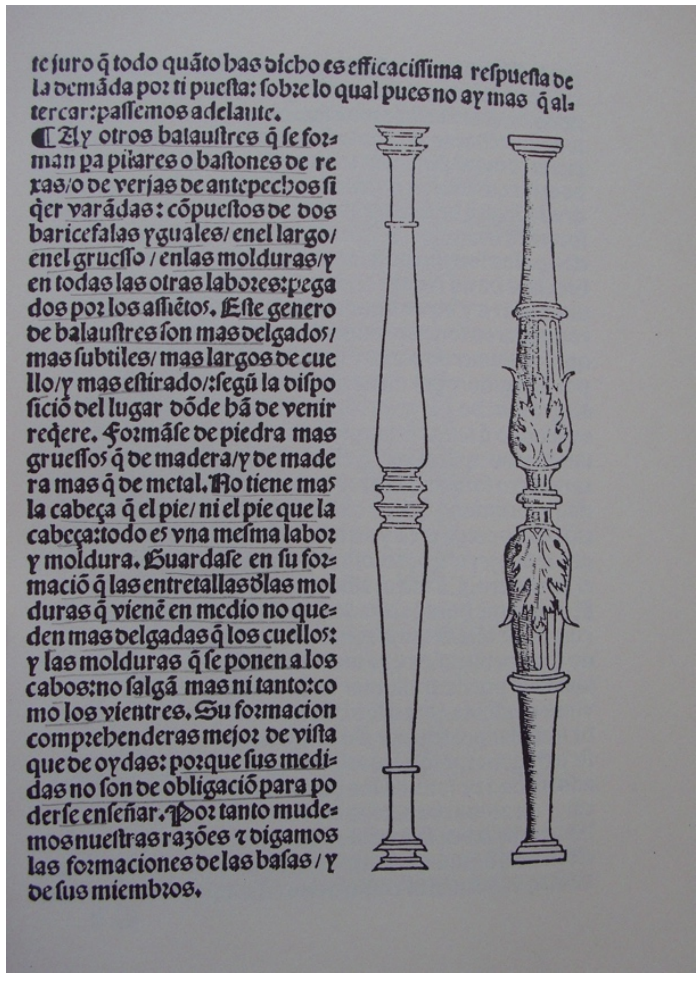

Fig. 9. Balaustre según diseño de Diego de Sagredo. Fuente: Sagredo, D. de, [1526] 1976. Medidas del Romano, s.p.

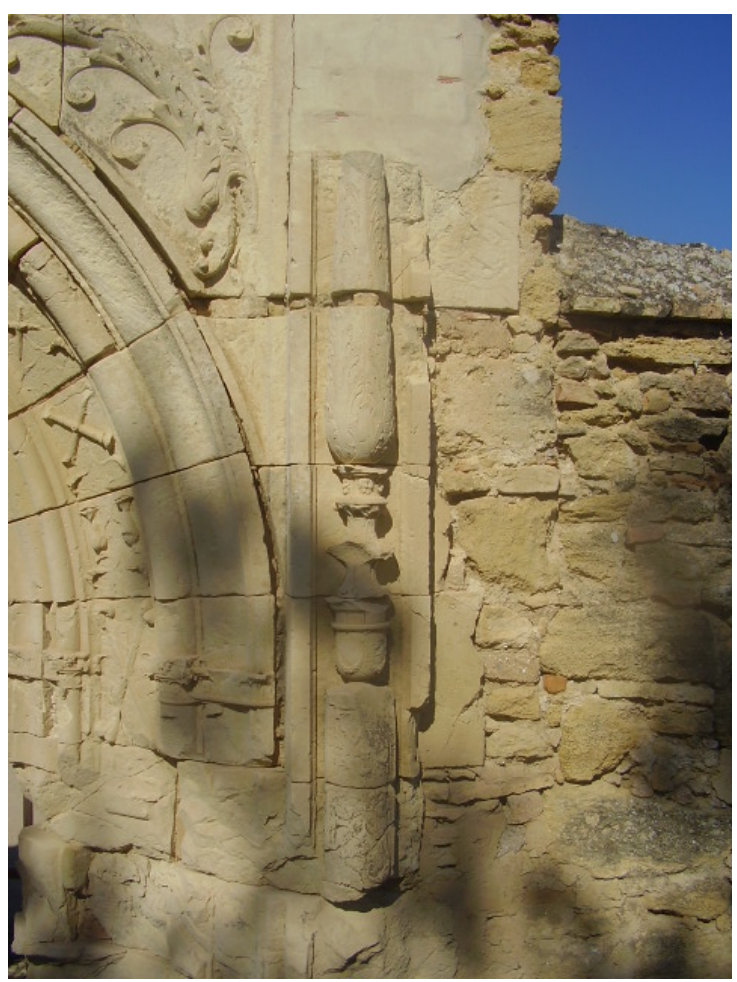

Fig. 10. Balaustre de la portada del convento de San Lorenzo. Fuente: fotografía de la autora.

presentan, igualmente, un repertorio vegetal eminentemente italianizante, como las flores que adornan la estrechez de las molduras cóncavas, mientras que en la convexa inferior se aprecia una guirnalda que se articula en diferentes secciones. Sobre cada balaustre, como anteriormente se ha indicado, se encontraba un capitel jónico con volutas dispuestas en diagonal.

La portada culmina en un entablamento que, manteniendo las proporciones, sentido geométrico y orden que se aprecia en todo el conjunto, reafirma, más si cabe, la inspiración y carácter clasicista de su diseño. El elemento ornamental que lo preside a modo de eje de simetría es el escudo de armas de la II marquesa de Priego, dejando testimonio de su promoción artística en el convento franciscano al representarlo en un lugar preferencial del acceso al recinto religioso (fig. 11). De esta forma, la aristócrata muestra ante sus súbditos el poder político y económico que poseía, pero también del humanismo que ostentaba a través de las obras de arte que promocionaba.

La heráldica, que en su conjunto tiene un diámetro de 70 centímetros, se ajusta a las armas personales de Catalina Fernández de Córdoba y Enríquez, eludiendo cualquier elemento vinculado a su marido el conde de Feria. En efecto, según lo estipulado por ambos nobles en sus capitulaciones matrimoniales en diciembre de 1517, el escudo compartiría las armas de sus respectivas casas ${ }^{41}$. Sin embargo, la repentina viudedad de la aristócrata en 1528 y, fundamentalmente, su condición de heredera del linaje de los Fernández de Córdoba fueron los factores que entrañaron la desaparición de los atributos de la Casa de Feria, que fueron suplantados por los correspondientes de la Casa de los Enríquez, procedentes de la línea

${ }^{41}$ Fernández de Córdoba, 1954: 174-175. Al respecto se contempla: «Que el escudo de las armas de ambos fuese partido en cuartel y en los dos superiores estuviesen a mano derecha las armas de la Marquesa y a la izquierda las del Conde, y en los cuarteles inferiores al contrario y que el escudo abrazase el águila negra o sable, blasón antiguo de los señores de la Casa de la Marquesa». 


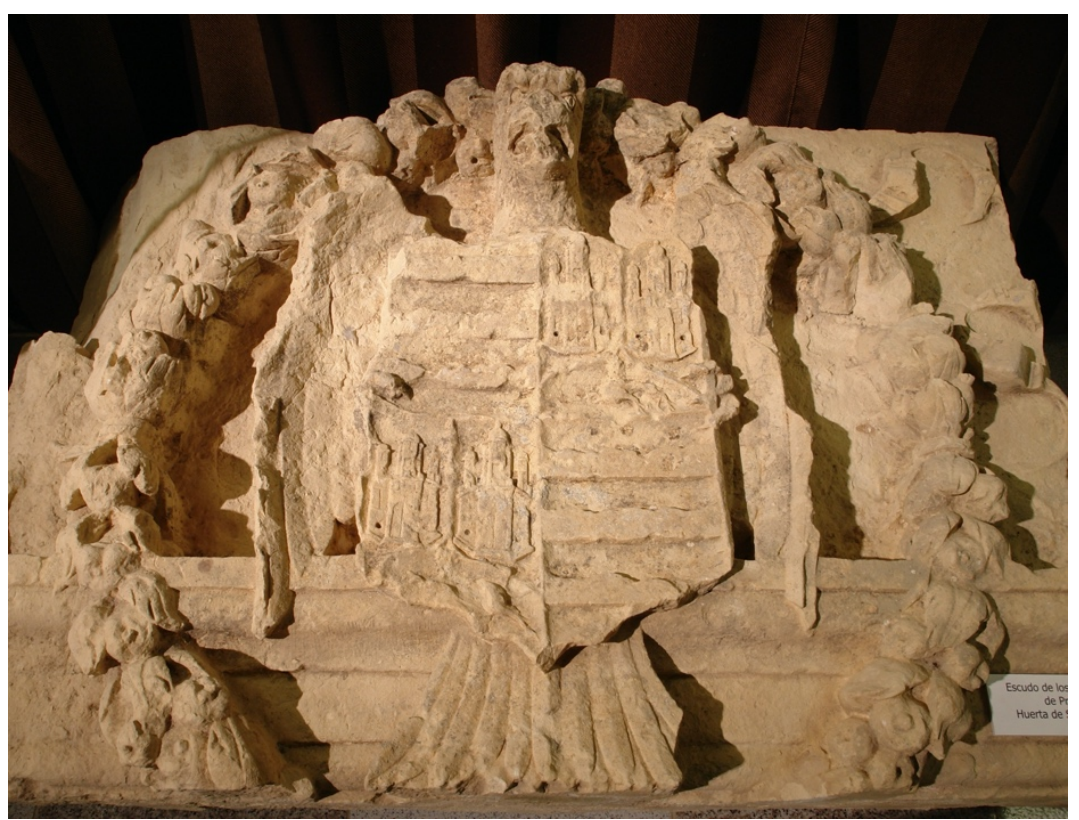

Fig. 11. Escudo de Catalina Fernández de Córdoba y Enríquez en la portada del convento de San Lorenzo. Montilla (Córdoba), Museo Histórico. Fuente: fotografía de la autora.

materna de la marquesa Catalina. Estas modificaciones definieron sus armas de la siguiente manera: escudo cuartelado en cruz, primero y cuarto de oro con tres fajas de gules, correspondiendo al linaje de los Fernández de Córdoba. Segundo y tercero mantelado; los superiores de gules con sendos castillos de oro aclarado de azur, mientras que el inferior - de plata- con león rampante en púrpura, manifestando el linaje de los Enríquez. Como soporte del escudo se encuentra el águila de sable, emblema que, desde sus orígenes en el siglo XIII, ha representado a la Casa de Aguilar. El ave se muestra con las alas extendidas y la cola abierta, mientras que sus garras sostienen el escudo por la mitad horizontal. La cabeza se dirige al frente, mostrando su axialidad en el pico y mirándonos de forma desafiante ${ }^{42}$. El escudo está orlado por una por una delicada guirnalda vegetal con frutos ${ }^{43}$.

Como puede apreciarse con respecto al resto del repertorio escultórico de la portada, el modelado del escudo alcanza el máximo resalte volumétrico del conjunto. Asimismo, en la guirnalda que envuelve la heráldica se advierte una delicadeza de talla excepcional, evocando la frescura y clasicismo italianizante. La minuciosidad de su factura, tanto en el ramaje como en los frutos que la componen, queda demostrada igualmente en la argolla pétrea que, dispuesta en la parte inferior y ayudándose de unas cintas semejantes a las que encontramos en los instrumentos de la Pasión, simula soportar la guirnalda en el frontón, como si se tratase de una decoración efímera petrificada.

Si hay un aspecto que destaque en la configuración del escudo es su vinculación con la plástica romana, concretamente con un relieve que representa a un águila imperial inserto en una corona de laurel, incluyendo en su representación el motivo de las cintas que atan la corona, también en la parte inferior. Se trata de una obra que, según García Bellido, es datada en el siglo II y procedente del foro de Trajano ${ }^{44}$, aunque posteriormente fue trasladada hasta el atrio de la íglesia de los Santos Apóstoles de Roma (fig. 12).

2 Similar heráldica se encuentra en la portada principal de la iglesia conventual de Santa Clara.

43 Tras el expolio que sufrió la portada en 1999, el escudo forma parte de los fondos museísticos del Museo Histórico de Montilla.

${ }^{44}$ García Bellido, 1990: 363 y 380. 


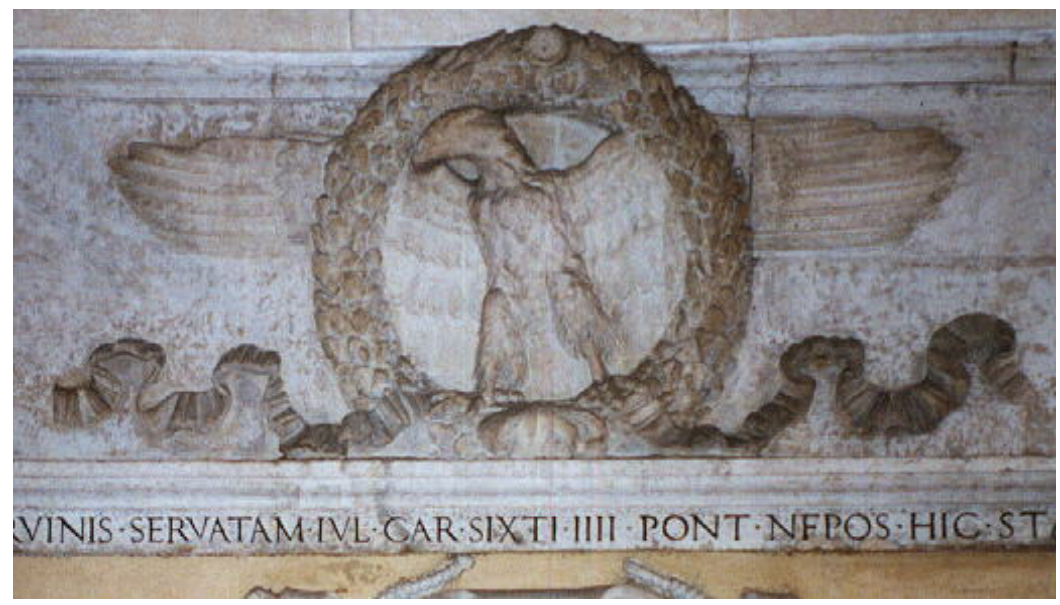

Fig. 12. Aguila imperial procedente del foro de Trajano. Roma, Iglesia de los Santos Apóstoles. Fuente: García Bellido, 1990: 363.

Otras figuraciones de inspiración clásica también quedan presentes en el arquitrabe. De esta forma, flanqueando al motivo heráldico se encuentran sendos putti alados, en posición de perfil y tangentes con respecto a aquel (fig. 13). Estos infantes, cuyo torso se curva para adaptarse al espacio del sillar, parecen prolongarse lateralmente en un roleo de mórbidos tallos erizados - los cuales siguen una tendencia circular-, trasformando su medio cuerpo inferior de manera que se asemeja a un ser fantástico. Se trata de la interpretación de un asunto iconográfico localizado en un detalle perteneciente al relieve del mausoleo de los Haterii, del siglo II. En cuanto a la utilización de los roleos, volvemos a encontrar esta tipología ornamental en los que se encuentran en distintos relieves de época alto imperial, creando una secuencia de rítmicas espirales ${ }^{45}$. Pero, además, este elemento decorativo tuvo una importante difusión en el primer renacimiento español, puesto que aparece representado en la fachada de la Universidad de Salamanca, en concreto sobre el medallón que efigia a los Reyes Católicos. Asimismo, un diseño con notables analogías con respecto al entablamento de la portada de San Lorenzo se ha encontrado en el perteneciente a la portada de la Casa de las Muertes, también en la ciudad del Tormes.

Flanqueando el entablamento, el motivo utilizado en el espacio correspondiente a la prolongación superior de las pilastras cajeadas es un candelieri de estética romana. Simulando un surtidor, establece una rigurosa simetría y permite que unas aves zancudas beban el agua que brota del mismo. Esta representación desprende un notable italianismo, volviendo a reiterarnos en la excepcional desenvoltura en el lenguaje clásico que gozó el maestro escultor que realizara este monumento. Como motivo de inspiración, de nuevo se ha localizado un relieve que se encuentra en la tumba de los Haterii, donde - como advierte García Bellidolos pajarillos picotean lo alto del candelero, eje de la composición ${ }^{46}$.

\section{Conclusiones}

La portada del convento de San Lorenzo de Montilla manifiesta plenamente la promoción artística desplegada por la II marquesa de Priego en este establecimiento franciscano. Una vez realizado el análisis arquitectónico e iconográfico de la portada objeto de estudio, podemos afirmar que su configuración responde a los dictámenes de los maestros renacentistas. Su estructura recupera la morfología de los arcos triunfales construidos durante el Imperio, al tiempo que obedece al concepto de canon clásico y geometría que identifica

\footnotetext{
45 García Bellido, 1990: 209-210.
}

46 García Bellido, 1990: 326-327. 


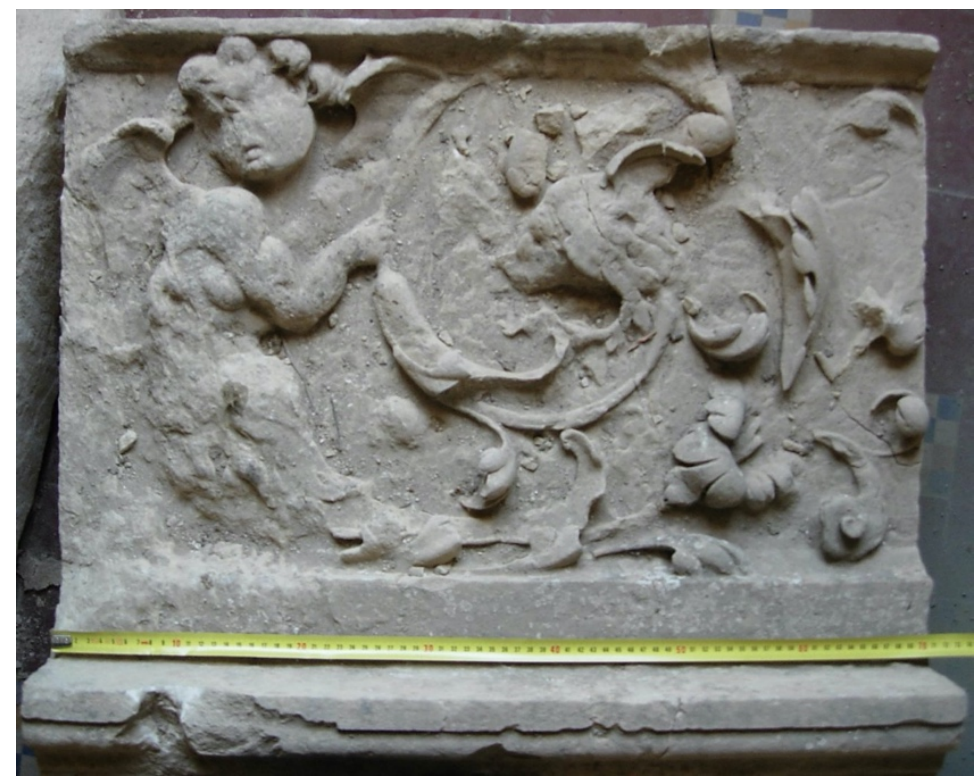

Fig. 13. Putti del entablamento de la portada del convento de San Lorenzo. Montilla (Córdoba). Fuente: fotografía de Arturo Ramírez Laguna.

las creaciones del renacimiento, difundidas en el área cordobesa en los diseños de portadas que se deben a Hernán Ruiz II, aunque también se advierten ciertos elementos más tempranos. En su programa ornamental coexisten elementos cristianos con otros de origen pagano, manifestando el ideal de la concordatio renacentista. De esta forma se compaginan la representación de los instrumentos de la Pasión — de una raigambre iconográfica cristiana sobradamente reconocida a lo largo de la historia del arte-, junto con otros motivos cuya procedencia se encuentra en obras clásicas altoimperiales, siendo el colofón que manifiesta cómo los artistas del renacimiento interpretaron la Antigüedad clásica a través de sus modelos de inspiración.

Aunque son escasas las similitudes plásticas que se han encontrado con respecto a otras edificaciones partícipes de similar movimiento cultural en el entorno provincial, sin embargo, se han localizado diversas conexiones iconográficas con representaciones concretas pertenecientes al foco salmantino. Estas concomitancias estilísticas nos inducen a pensar, aunque con cierta cautela y careciendo de documentación que lo justifique, que, probablemente, don Lorenzo Suárez de Figueroa y Córdoba (1528-1605) tuviera alguna implicación en este encargo. En efecto, el hijo menor de doña Catalina adquirió una sólida formación humanística en la Universidad de Salamanca y, posteriormente, tomó hábito dominico en el convento de San Esteban de la misma ciudad, de modo que hubo de tener un conocimiento directo y aprecio ciertamente elevado de las creaciones del primer renacimiento que por entonces estaban en vigencia. Además, no olvidemos que fue el ilustre dominico quien se encargó de oficiar las honras fúnebres cuando se trasladaron los restos de los marqueses de Priego hasta el panteón del convento franciscano en $1566^{47}$. En este sentido, pudiera ser que don Lorenzo Suárez de Figueroa asesorara a su madre sobre la elección de maestro, que sin duda tendría una elevada formación, y, principalmente, en el discurso iconográfico de la portada de San Lorenzo, en la que exalta la identidad de la heredera del linaje a través de la utilización de motivos de reconocida firmeza imperial.

\footnotetext{
${ }^{47}$ Fernández de Córdoba, 1954: 178-179.
} 


\section{Bibliografía}

Bellido Vela, E.: "El arco de San Lorenzo de la ciudad de Montilla: análisis de sus elementos artísticos y ejemplo de mecenazgo renacentista". En: Peláez del Rosal, Manuel (ed.) (2009): XIII Curso de Verano el Franciscanismo en Andalucía. Córdoba: El Almendro, (2009), pp. 255-275.

Cuadrado Sánchez, M.: "La arquitectura franciscana en España (siglos XIII y XIV)". En: Archivo Ibero Americano, 201-202 [Núm.], Madrid, (1991), pp. 15-70.

Cuadrado Sánchez, M.: "La arquitectura franciscana en España (siglos XIII y XIV)". En: Archivo Ibero Americano, 203-204 [Núm.], Madrid, (1991), pp. 479-552.

Copado, B.: La Compañia en Montilla. Málaga: Artes Gráficas Alcalá. 1944.

Cortés López, M. E.: "El impulso de la orden Franciscana en la configuración del Vía Crucis Gallego". En [s.n] (2012) Actas del VI Seminario Internacional Luso-Brasileiro. Os franciscanos no mundo portugués. O leado franciscano. Oporto: CEPESE, (2012), p. 757-782.

Checa Cremades, F.: Pintura y escultura del Renacimiento en España, 1450-1600. Madrid: Cátedra. (1983).

De la Banda y Vargas, A.: El arquitecto Hernán Ruiz. II. Sevilla: Diputación Provincial. (1974).

De la Torre y del Cerro, J.: Registro documental de pintores cordobeses. Córdoba: Diputación Provincial. (1988).

Fernández de Córdoba, F.: Historia y Descendencia de la Casa de Córdoba. Córdoba: Real Academia de Córdoba de Ciencias, Bellas Letras y Nobles Artes. (1954).

García Bellido, A.: Arte Romano. Madrid: CSIC. (1990).

García Ros, V.: Los franciscanos y la arquitectura. Valencia: Asís. (2000).

Garramiola Prieto, E.: Montilla. Guía Histórica, Artística y Cultural. Córdoba: El Almendro. (1982).

Garramiola Prieto, E.: "Documentos montillanos para la historia del post-renacimiento cordobés (1553-1602)". En: [s.n.] (1986):Notas para la Historia de Córdoba y su provincia. Córdoba: Asociación Provincial Cordobesa de Cronistas Oficiales. (1986).

González Serrano, P.: “Arquitectura prerromana y romana”. En: Morales, José Luis/Rincón, Wifredo (eds.) (1985): Historia de la Arquitectura Española. Barcelona: Planeta, (1985), pp. 31-106.

Heydenreich, L./Lotz, W.: Arquitectura en Italia (1400-1600). Madrid: Cátedra. 1996.

Jiménez Espejo, F. J.: "Estudio inicial sobre la influencia de la Geología en la distribución de los yacimientos en el término municipal de Montilla". En: Boletín de la Asociación provincial de Museos Locales de Córdoba, 5[Núm.], Córdoba, (2004), pp. 105-113.

Morte Molina, J.: Montilla. Apuntes históricos de esta ciudad. Montilla: Ayuntamiento de Montilla. (1982).

Navascués Palacio, P.: "El manuscrito de arquitectura de Hernán Ruiz el Joven”. En: Archivo Español de Arte, 44 [vol.], 175 [Núm.], Madrid, (1971), pp. 295-321.

Nieto, V./Checa, F.: El Renacimiento. Formación y crisis del modelo clásico. Madrid: Istmo. (1993).

Ramírez de las Casas Deza, L. M ${ }^{\mathrm{a}}$.: Corografía histórico estadística de la provincia y obispado de Córdoba. Córdoba: Monte de Piedad y Caja de Ahorros de Córdoba. (1986).

Revenga Domínguez, P.: "Un alboroto magnífico”. En: Sáez, Olga (ed.) (2016): Palas y las Musas. Diálogos entre la ciencia y el arte. México: Siglo XXI, (2016), pp. 9-27. 
Sagredo, D.: Medidas del Romano (1526) [Ed. facsímil]. En: Cervera, Luis (ed.). Valencia: Albatros Ediciones, (1976).

Sebastián, S.: "Entorno al primer Renacimiento". En: Príncipe de Viana. Anejo, 12 [Núm.], Pamplona, (1991), pp. 103-110.

Torres, A.: Chrónica de la Santa Provincia de Granada. Madrid: Imprenta de Juan Infançon. (1683).

Villar Movellán, A.: "La arquitectura del Quinientos". En: Guarinos, Marcel (dir.) (1986): Córdoba y su provincia. Sevilla: Gever, (1986), pp. 209-233.

Vindel, F.: Escudos y marcas de impresores y libreros de España durante los siglos XV al XX. Barcelona: Orbis. (1942). 